\title{
Global ecological regionalization of 15 Illicium species: nature sources of shikimic acid
}

\author{
Xiang Zhang ${ }^{1+}$, Xiangxiao Meng ${ }^{2+}$, Jie $\mathrm{Wu}^{2+}$, Linfang Huang ${ }^{1 *}$ and Shilin Chen ${ }^{2 *}$
}

\begin{abstract}
Background: Illicium plants are relevant officinal and ornamental species that are native in Eastern Asia, and they are the main sources of shikimic acid. Shikimic acid is an important component of Tamiflu, which is recognized for its ability to resist avian influenza by the World Health Organization. To determine areas where 15 Illicium species can be grown and to understand the importance of species diversity, we should enhance the prediction of suitable areas.

Methods: In this study, the global potential distribution of 15 Illicium species was predicted using a geographic information system for global medicinal plants.

Results: Results showed that the possible suitable areas for these plants in China covered $1357.68 \times 10^{4} \mathrm{~km}^{2}(56 \%)$, and the second-largest area spanning $527.42 \times 10^{4} \mathrm{~km}^{2}$ was found in the United States. Illicium verum Hook, an edible species with the highest shikimic acid content among them, grew in areas of $59.92 \times 10^{4}(48 \%), 64.04 \times 10^{4}(19 \%)$, and $60.53 \times 10^{4} \mathrm{~km}^{2}(18 \%)$ in China, the United States, and Brazil, respectively. Illicium.difengpi B. N. Chamg, an endangered species, was distributed in an area of $19.03 \times 10^{4} \mathrm{~km}^{2}$ or $95 \%$ of the total area in China.
\end{abstract}

Conclusions: This research provided a guarantee for the demand of Tamiflu, presented strategies that helped protect endangered species, and provided a reference for species cultivation and introduction.

Keywords: Shikimic acid, Illicium plants, Geographic information system for global medicinal plants, Ecological suitable areas

\section{Background}

Shikimic acid (3,4,5-trihydroxy-1-cyclohexene-1-carboxylic acid) is commonly known as the main natural raw material of Tamiflu, which is recognized as the first drug to treat avian influenza in clinical settings [1-3]. The main sources of shikimic acid are Illicium plants, which are naturally distributed in Southeast China, the United States, Burma, and Vietnam [4] (Table 1). A total of 34 kinds of Illicium plants exist, and 15 of them (I. verum Hook. f., I. henryi Diels, I. majus Hook. f. \& Thoms., I. simonsii Maxim., I. micranthum Dunn, I. dunnianum Tutch., I. lanceolatum A. C. Smith, I. fargesii Finet \& Gagnep, I. jiadifengpi B. N. Chang, I. difengpi B. N.

\footnotetext{
*Correspondence: Ifhuang@implad.ac.cn; slchen@icmm.ac.cn ${ }^{+}$Xiang Zhang, Xiangxiao Meng and Jie Wu are co-first authors 1 Institute of Medicinal Plant Development, Chinese Academy of Medical Sciences and Peking Union Medical College, Beijing 100193, China

${ }^{2}$ Institute of Chinese Materia Medica, China Academy of Chinese Medical Sciences, Beijing 100700, China
}

Chamg, I. ternstroemioides A. C. Smith, I. macranthum A. C. Smit, I. oligandrum Merr, et al. Chun, I. brevistylum A. C. Smith, and I. pachyphyllum A. C. Smith) can be used as Chinese herbal medicines for the treatment of rheumatoid arthritis, injuries, abdominal distention, and vomiting $[5,6]$. Currently, they are mainly distributed in South and Southeast China, such as Hunan, Fujian and Guangxi. Among these species, I. verum Hook. f., an edible plant which is listed in the Pharmacopoeia of China (2015 edition) and European Pharmacopoeia (7th edition). I. difengpi B. N. Chamg is listed in the Pharmacopoeia of China (2015 edition) and recorded in the Information System of Chinese Rare and Endangered Plants (http://rep.iplant.cn/protlist).

As traditional herbal medicines, Illicium plants have been technically investigated on active ingredient synthesis. Here are two ways for shikimic acid synthesis including biosynthetic pathways and chemical pathways. Figure 1a shows the shikimate pathway, which serves as

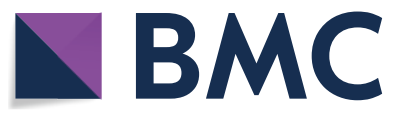

(c) The Author(s) 2018. This article is distributed under the terms of the Creative Commons Attribution 4.0 International License (http://creativecommons.org/licenses/by/4.0/), which permits unrestricted use, distribution, and reproduction in any medium, provided you give appropriate credit to the original author(s) and the source, provide a link to the Creative Commons license, and indicate if changes were made. The Creative Commons Public Domain Dedication waiver (http://creativecommons.org/ publicdomain/zero/1.0/) applies to the data made available in this article, unless otherwise stated. 
Table 1 Distribution points of 15 kinds of Illicium plants

\begin{tabular}{|c|c|c|}
\hline Latin names of species & Distribution & $\begin{array}{l}\text { Sampling } \\
\text { points }\end{array}$ \\
\hline I. verum & $\begin{array}{l}\text { In China, western and southern of Guangxi, southern of Zhejiang, Jiangxi, Hunan and Chongqing, south-central } \\
\text { Fujian, southwest of Guangdong and Guizhou, southeast of Hainan, Yunnan, etc. }\end{array}$ & 61 \\
\hline I. henryi & $\begin{array}{l}\text { In China, Anhui, Jiangxi, Fujian, Henan, Guangdong, Guangxi, Chongqing, Yunnan, southern of Shanxi and } \\
\text { Gansu, northern of Hubei, from west to northwest of Hubei, from east to southeast of Sichuan, from eastern to } \\
\text { northern of Guizhou, etc. }\end{array}$ & 171 \\
\hline I. majus & $\begin{array}{l}\text { Guangxi, Guizhou, Chongqing, Yunnan, Hunan, southwest of Hubei, from western to northern of Guangdong, } \\
\text { from central to south central of Sichuan in China, southern of Burma, northern of Vietnam, etc. }\end{array}$ & 128 \\
\hline I. simonsii & $\begin{array}{l}\text { Southwest of Sichuan (Xichang, Huili, Puge),from northwest to southeast of Guizhou, northwest, northeast and } \\
\text { central Yunnan in China, northern of Burma, northeast of India, etc. }\end{array}$ & 95 \\
\hline I. micranthum & $\begin{array}{l}\text { In China, Hunan, Guangdong, Hongkong, Sichuan, Guizhou, Chongqing, Yunnan, western of Hubei, from central } \\
\text { to northern of Guangxi, etc. }\end{array}$ & 93 \\
\hline I. dunnianum & $\begin{array}{l}\text { In China, Guangdong, Hongkong, Guangxi, southern of Fujian, southwest of Hunan, southern and southwest of } \\
\text { Guizhou, southeast of Sichuan, etc. }\end{array}$ & 80 \\
\hline I. lanceolatum & In China, Anhui, Zhejiang, Jiangxi, Fujian, Hubei, Hunan, Guizhou, southern of Jiangsu, southeast of Henan, etc. & 76 \\
\hline I. fargesii & $\begin{array}{l}\text { In China, Chongqing, western of Hubei, northeast of Yunnan, from northwest to southwest of Hunan, from } \\
\text { northern to northeast of Guangxi, from eastern to northeast of Guizhou, from eastern to central of Sichuan, } \\
\text { etc. }\end{array}$ & 72 \\
\hline I. jiadifengpi & $\begin{array}{l}\text { In China, Jiangxi, Fujian, Hongkong, southern of Anhui, southwest of Zhejiang, northeast of Guangxin, northern } \\
\text { of Guangdong, southeast of Hubei, from southern to eastern of Hunan, etc. }\end{array}$ & 69 \\
\hline 1. difengpi & In China, Guangxin, southeast of Yunnan, etc. & 61 \\
\hline I. ternstroemioides & In China, Fujian, Guangdong, Hongkong, Guangxi, southern of Hunan, southeast of Yunnan, etc. & 58 \\
\hline I. macranthum & In China, southeast and western of Yunnan, southeast of Tibet, etc. & 42 \\
\hline I. oligandrum & South of Guangxi, Hainan in China, Vietnam, etc. & 37 \\
\hline 1. brevisty/um & In China, Guangdong, Guangxi, southern of Hunan, southeast of Yunnan, Fujian, Hongkong, etc. & 29 \\
\hline I. pachyphyllum & In China, southwest of Guangdong and Hunan, southeast and northeast of Guizhou, etc. & 22 \\
\hline
\end{tabular}

a<smiles>OC[C@H]1C[C@@H](O)[C@H](O)[C@H](O)[C@@H]1O</smiles>


acid

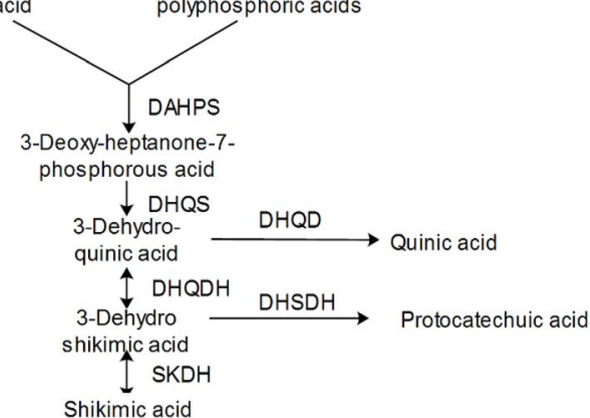

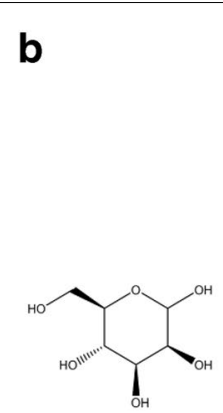
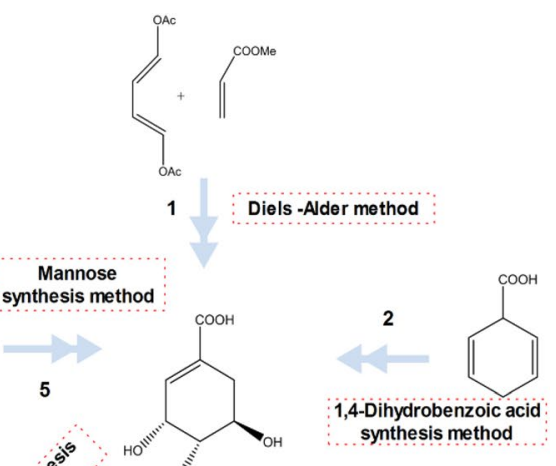

Fig. 1 The biosynthesis pathways (a) and chemical synthesis pathways (b) of shikimic acid

an intermediate product in this pathway to form essential aromatic amino acids [7-11]. The whole biosynthetic pathway of shikimic acid involves six steps with uncontrollable conditions and a low product yield of $36 \%$. Besides, five routes of shikimic acid synthesis (Fig. 1b) have been reported [12-14]. Diels-Alder method [1,9] 
possess a low product yield (15\%). Quinic acid is used to produce shikimic acid with more than 7 days [8]. The route with the raw material of mannose which is a novel and simplified strategy has five steps and a low product yield of $25 \%$ [9]. Tamiflu plays a key role in resisting avian influenza [10, 15]. Tamiflu synthesis has been widely examined which need shikimic acid as raw material, and research on the suitable distribution areas of the 15 Illicium species has revealed that these plants as natural sources of shikimic acid can be efficient materials to obtain Tamiflu. Nevertheless, the product yield of shikimic acid is low and synthetic procedure is complex, and the possible ecologically suitable areas for Illicium plants are largely unknown $[16,17]$.

We collated high-quality ground-point data to analyze favorable growing areas for future applications, and we used seven environmental factors to understand the current climate conditions for Illicium plant farming. According to ecological niche, we can assess the habitats which are conducive for the growth of the 15 Illicium species by using a geographic information system for global medicinal plants (GMPGIS), a software could predict the potential distribution of species based on the climate factors analysis and has been applied in many species such as Panax ginseng [18]. Our analyses primarily focused on identifying their suitable habitats of Illicium species at a global scale and determining appropriate areas where they could be introduced and cultivated worldwide. This study could enhance our understanding of the distribution range of Illicium plants, address problems related to shikimic acid supply, and provide strategies to help protect I. difengpi B. N. Chamg, which is an endangered species.

\section{Methods}

\section{Data sources of target species}

Illicium plants are evergreen trees or shrubs, and they are suited to mountain climate. In this research, the occurrence data points of modeling species distribution were carefully screened to reduce sampling bias and sampling errors from four resources [7, 19]: (1) Chinese Virtual Herbarium (CVH) (http://www.cvh.ac.cn/); (2) National Specimen Information Infrastructure (NSII) (http:// www.nsii.org.cn/2017/home.php); (3) literatures; and (4) field work. The number of sampling points is listed in Table 1. Using the website http://www.gpsspg.com/maps. $\mathrm{htm}$, we can obtain the latitude and longitude of each point, and the range of the latitude and longitude of the sampling points is shown in Additional file 1: Table S1.

\section{Environmental variables for modeling}

Environmental variables play important roles in determining the potential species' distribution at a global scale.
Hence, these variables are widely used to predict the possible suitable habitats of species. In the present study, the environmental characteristics of 15 Illicium species were characterized by determining seven environmental variables (annual mean temperature, mean temperature of the coldest quarter, annual precipitation, mean temperature of the warmest quarter, humidity, annual radiation, and soil), which were examined according to statistics, ecology, and botany, as well as their close relationship with plant growth.

\section{GMPGIS modeling}

We modeled the potential regions of the 15 Illicium species by using the GMPGIS. This system has been verified successfully and has been used to predict potential distributions of many plant species, such as Panax ginseng C.A. Mey and Panax notoginseng (Burk.) F. H. et al. in China $[18,20,21]$. The following equations were utilized during the prediction of suitable distribution of the 15 Illicium species.

Data were standardized as follows:

$$
\chi^{\prime}=\frac{\chi-\min }{\max -\min }
$$

Similarity clustering analysis was conducted using the following equation:

$$
\begin{aligned}
\mathrm{d}_{\mathrm{ij}} & =\sqrt{\left(\chi_{11}-\chi_{12}\right)^{2}+\left(\chi_{12}-\chi_{22}\right)^{2}+\mathrm{L}+\left(\chi_{\mathrm{p} 1}-\chi_{\mathrm{p} 2}\right)^{2}} \\
& =\left[\sum \frac{\mathrm{p}}{\mathrm{k}=1}\left(\chi_{\mathrm{ki}}-\chi_{\mathrm{kj}}\right)^{2}\right]^{\frac{1}{2}}
\end{aligned}
$$

According to the results of distance calculation $\left[\operatorname{Mind}_{i p}\right.$ $\left.\operatorname{Maxd}_{i j}\right]$, we reclassified the distance raster, and the areas at $99.9 \%$ similarity were considered the suitable distribution with maximum similarities. Besides, after the intersection between the distance layer which is reclassified and the soil layer, the coincident suitable areas for climate and soil conditions could be obtained.

The Minimum Standards of Reporting Checklist contains details of the experimental design, and statistics, and resources used in this study (Additional file 2).

\section{Results}

Analysis of seven environmental variables

The specific ranges of the seven environmental variables of the 15 Illicium species are shown in Table 2. Different species exist in various soil types. The boxplots containing six environmental variables of the 15 Illicium species are illustrated in Fig. 2. Most of the variables showed large ranges in group 1 followed by 15 , especially annual mean temperature, mean temperature of the coldest quarter, and annual precipitation. 
Table 2 Range values of the environmental variables for 15 kinds of Illicium plants

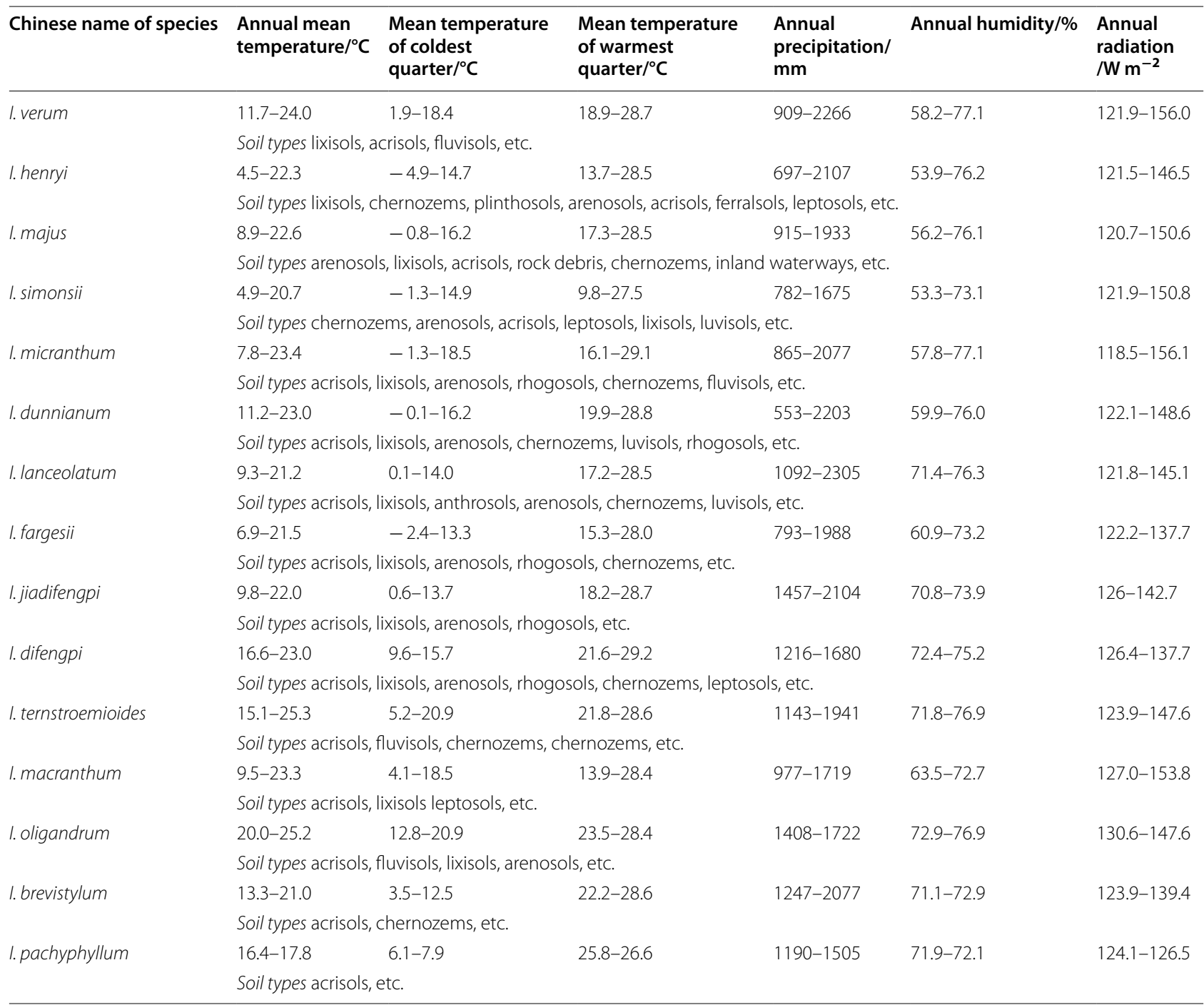

These significant differences could be attributed to different growth environments required by various species.

\section{Ecological niche}

Each environmental variable' range was divided into six segments on average, and the area $\left(\mathrm{km}^{2}\right)$ of each segment for the 15 Illicium species is shown in Fig. 3. These plants were widely distributed at annual mean temperature of $11.5-22.0{ }^{\circ} \mathrm{C}$, mean temperature of $-0.7-16.9{ }^{\circ} \mathrm{C}$ in the coldest quarter, and annual precipitation of 551-2016 mm. Furthermore, the potential suitable areas were larger at a mean temperature of $19.6-29.4^{\circ} \mathrm{C}$ in the warmest quarter, humidity of $61.2-$ $75.2 \%$, and annual radiation of $124.7-156.2 \mathrm{~W} \mathrm{~m}^{2}$.

\section{Analysis of the suitable distribution of the 15 Illicium species}

The suitable habitat maps based on the occurrence points of the 15 Illicium species in CVH, NSII databases, and field work are shown in Figs. 4 and 5 and in Additional file 3: Figure S1. The 15 Illicium species are mainly located in the latitude range of $45^{\circ} \mathrm{S}-45^{\circ} \mathrm{N}$, which is south and southeast of China, east of the USA, and south of Brazil. The core area in China where these plants are mainly distributed is $1357.68 \times 10^{4} \mathrm{~km}^{2}$, which ranks first and accounts for $56 \%$ of the total area worldwide. This ranking is followed by the USA with suitable areas of $527.42 \times 10^{4} \mathrm{~km}^{2}$. Figure 5 demonstrates that most of the areas in China are climatically suitable for I. difengpi, and only a small area spanning approximately $5 \%$ exists outside of China. Additional file 3: Figure S1 shows that $I$. pachyphyllumis located only in China. 

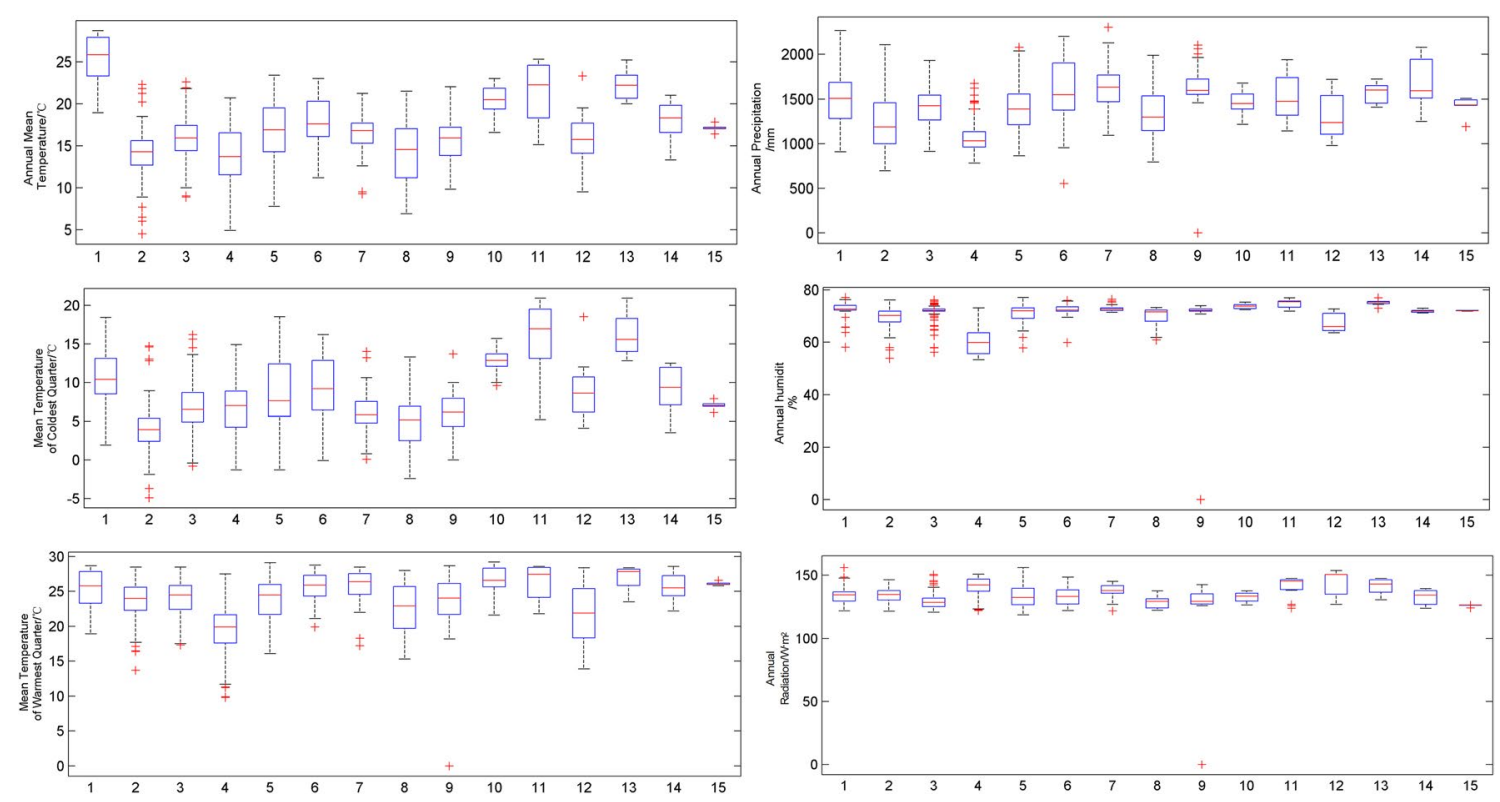

Fig. 2 Boxplot chart of the environmental variables. (1, I. verum; 2, I. henryi; 3, I. majus; 4, I. simonsii; 5, I. micranthum; 6, I. dunnianum; 7, I. lanceolatum; 8, I. fargesii; 9, I. jiadifengpi; 10, I. difengpi; 11, I. ternstroemioides; 12, I. macranthum; 13, I. oligandrum; 14, I. brevistylum; 15, I. pachyphyllum)

According to the map, the potential suitable habitats of the 15 Illicium species are found in six provinces in China (Fig. 6): Guangxi, Yunnan, Hunan, Guizhou, Sichuan, and Hubei. The specific suitable areas of each Illicium plant in China and other countries are shown in Additional file 1: Tables S2, S3.

a. I. verum Hook. f, an edible plant whose main producing area is Guangxi from China, which is recognized by National Health and Family Planning Commission, has a potential habitat with a total area of $377.9 \times 10^{4} \mathrm{~km}^{2}(19 \%)$ worldwide. It also covers approximately $64.04 \times 10^{4} \mathrm{~km}^{2}(18 \%)$ in the USA and $60.5 \times 10^{4} \mathrm{~km}^{2}(48 \%)$ in Brazil. The core areas are approximately $158.8 \times 10^{4} \mathrm{~km}^{2}$, which are mainly located in Yunnan, Guangxi, Hunan, and other places in China.

b. I. henryi Diels is a Chinese endemic species and its main producing areas are Shannxi and Gansu. Its favorable area measured approximately $407.4 \times 10^{4} \mathrm{~km}^{2}$ worldwide. It is distributed at $100.3 \times 10^{4} \mathrm{~km}^{2}(25 \%)$ in the USA, which has the second-largest coverage. This species also thrives at $23.3 \times 10^{4}(6 \%)$ and $16.4 \times 10^{4} \mathrm{~km}^{2}(4 \%)$ in France and Italy, respectively. The core areas cover $176.3 \times 10^{4} \mathrm{~km}^{2}(43 \%)$ in Yunnan, Guangxi, Guangdong, and Hunan in China.

c. I. majus Hook. $\mathrm{f}$ is mainly produced in Hunan which has a suitable habitat with an area of $275.9 \times 10^{4} \mathrm{~km}^{2}$ worldwide. Its favorable habitats in the USA, Brazil, and Japan cover $70.1 \times 10^{4}(25 \%)$, $13.1 \times 10^{4}(5 \%)$, and $6.5 \times 10^{4} \mathrm{~km}^{2}(6 \%)$, respectively. The core areas account for $59 \%$, or approximately $62.0 \times 10^{4} \mathrm{~km}^{2}$, of the land area in Guangxi, Yunnan, Hunan, and Sichuan in China.

d. I. simonsii Maxim is prevailingly occurred in Guizhou and Sichuan. It has a globally potential suitable area of $272.6 \times 10^{4} \mathrm{~km}^{2}$. It covers $78.9 \times 10^{4}(29 \%), 14.5 \times 10^{4}(5 \%), 14.0 \times 10^{4}(5 \%)$, and $5.7 \times 10^{4} \mathrm{~km}^{2}(3 \%)$ suitable areas in the USA, Spain, Italy, and France, respectively. The core areas spanning $113.5 \times 10^{4} \mathrm{~km}^{2}(42 \%)$ are mainly distributed in Yunnan, Hunan, and Guizhou provinces in China.

e. I. micranthum Dunn, is a native species chiefly in Fujian and Hubei, in China. The area of its suitable habitat is approximately $435.37 \times 10^{4} \mathrm{~km}^{2}$. Its distribution areas in the USA, Brazil, and Japan are $107.86 \times 10^{4}(24 \%), 56.38 \times 10^{4}(13 \%)$, and $9.04 \times 10^{4} \mathrm{~km}^{2}(13 \%)$, respectively. The core areas spanning $190.7 \times 10^{4} \mathrm{~km}^{2}(44 \%)$ are mainly located in Hunan, Guangxi, and Yunnan in China.

f. I. dunnianum Tutch, is a species endemic to China mainly in Fujian and Hunan. Its suitable habitat worldwide has a land area of $263.1 \times 10^{4} \mathrm{~km}^{2}$. This species also covers an area of $47.2 \times 10^{4} \mathrm{~km}^{2}$ $(18 \%)$ in the USA. The core areas spanning $62 \%$ are mainly distributed in China, especially in Guangxi, Hunan, and Jiangxi provinces. 
a

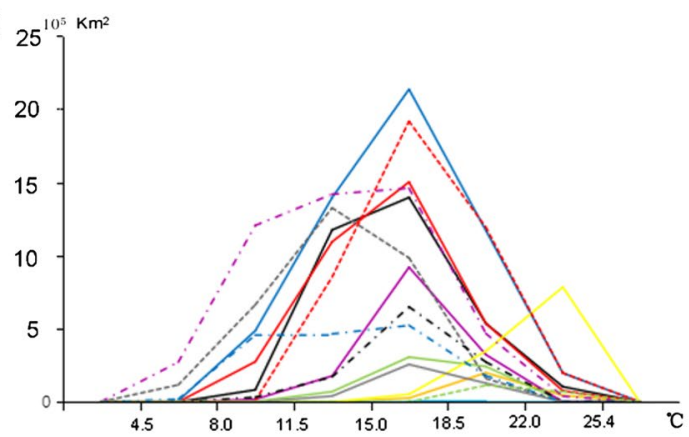

b



C

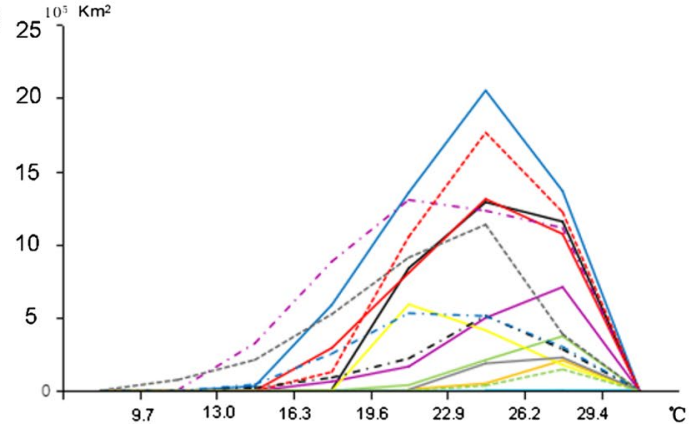

d

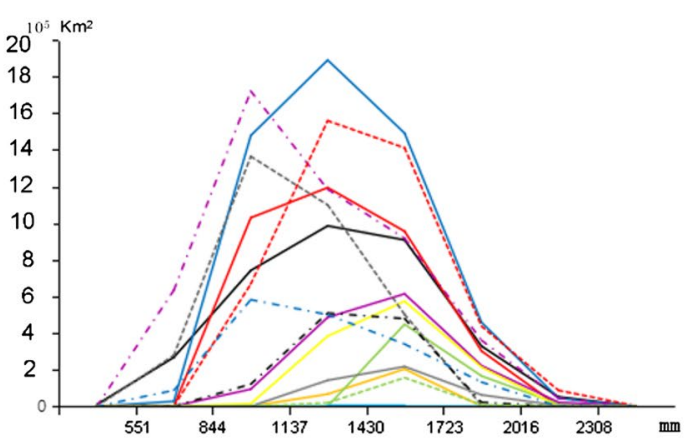

e $20^{10^{3}} \mathrm{~km}^{2}$

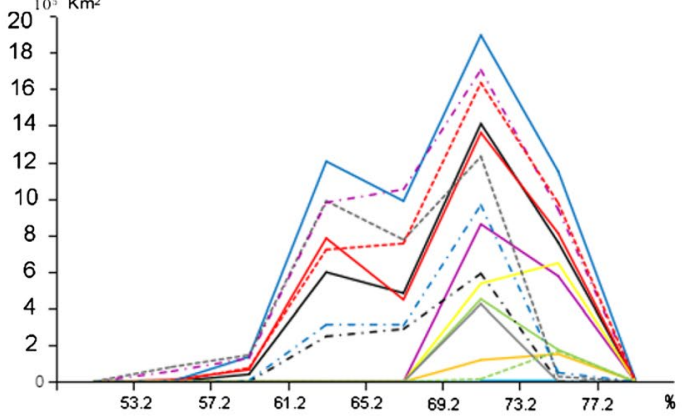

f $16^{10^{5}} \mathrm{~km}^{2}$

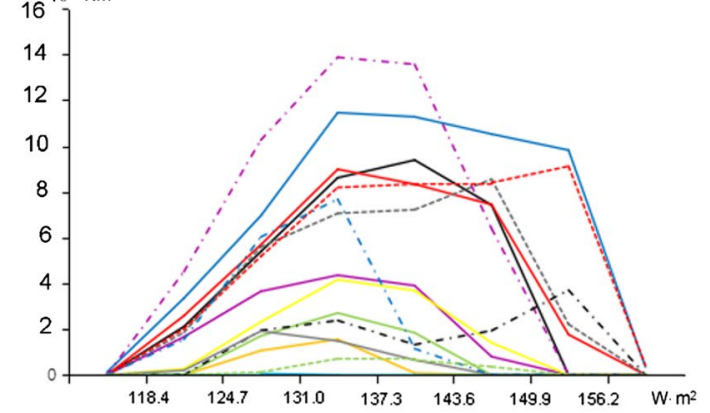

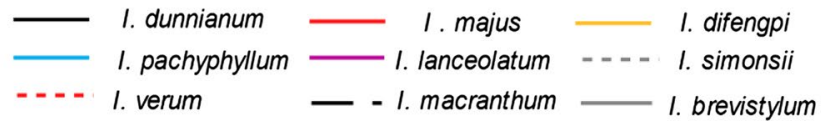
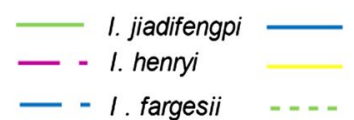

I. micranthum

I. ternstroemioides

1. oligandrum

Fig. 3 The ecological niche of every environmental variables. a Annual mean temperature; $\mathbf{b}$ mean temperature of coldest quarter; $\mathbf{c}$ mean temperature of warmest quarter; $\mathbf{d}$ annual precipitation; e annual humidity and annual radiation

g. I. lanceolatum A. C. Smith is a native species in China and mostly in Jiangsu and Anhui. It possess a potential suitable area of $109.1 \times 10^{4} \mathrm{~km}^{2}$ worldwide. This species covers an area of approximately $8 \%$ of the total distribution area in Brazil. It is also distributed in Vietnam, Japan, and the USA with respective areas of $1.4 \times 10^{4}, 1.6 \times 10^{4}$, and $0.2 \times 10^{4} \mathrm{~km}^{2}$, which account for $1 \%$. Its potential suitable habitat with an area of $95.1 \times 10^{4} \mathrm{~km}^{2}$ (87\%) is located in China, particularly in Hunan, Jiangxi, and Guangxi provinces. h. I. fargesii Finet \& Gagnep is a species endemic to China, its main producing areas are Guizhou and Hunan. It has a suitable area of $135.2 \times 10^{4} \mathrm{~km}^{2}$. This species covers $31.8 \times 10^{4}(24 \%)$ and $5.8 \times 10^{4}$ $\mathrm{km}^{2}(4 \%)$ in the USA and Japan. Its potential distribution area in China is $71.7 \times 10^{4} \mathrm{~km}^{2}(53 \%)$ spanning Guizhou, Hunan, and Guangxi provinces.

i. I. jiadifengpi B. N. Chang principally grows in Anhui and Zhejiang, which has a suitable habitat with an area of $45.4 \times 10^{4} \mathrm{~km}^{2}$ worldwide. This species respectively covers $0.6 \times 10^{4}$ and $0.5 \times 10^{4}$ 


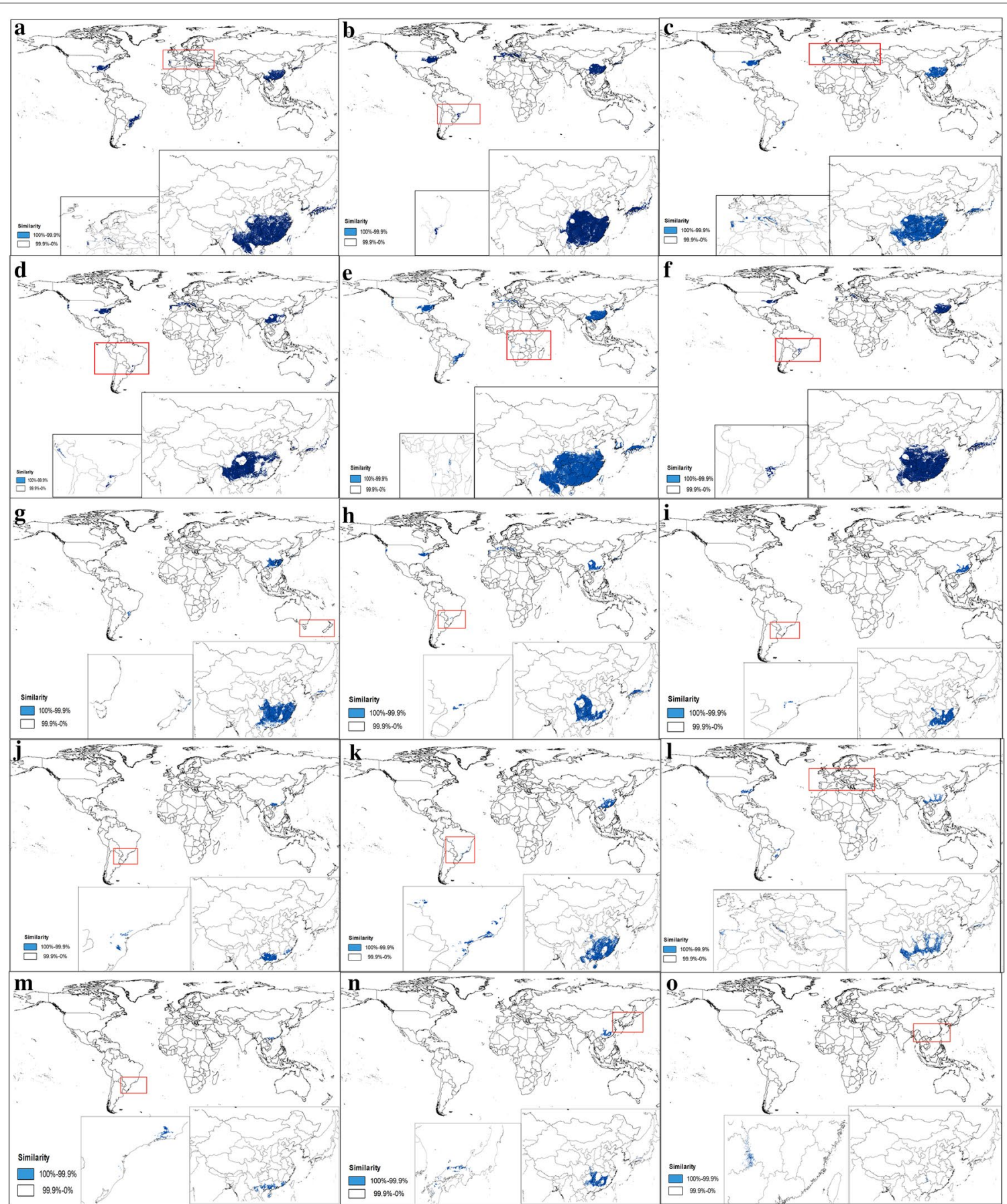

Fig. 4 Suitable areas in China and in the world of 15 illicium plants. (a I. verum; b I. henryi; $\mathbf{c}$ I. majus; $\mathbf{d}$ I. simonsii; e I. micranthum; $\mathbf{f}$ I. dunnianum; $\mathbf{g}$ I. lanceolatum; $\mathbf{h}$ I. fargesii; i I. jiadifengpi; $\mathbf{~ I . ~ d i f e n g p i ; ~} \mathbf{k}$. ternstroemioides; I. macranthum; $\mathbf{m}$ I. oligandrum; $\mathbf{n}$ I. brevistylum; o I. pachyphyllum) 

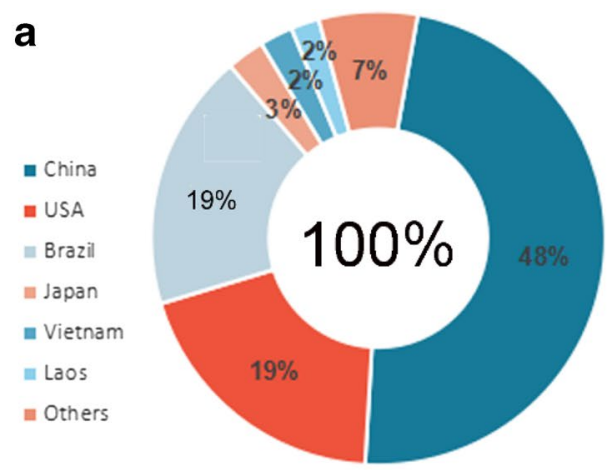

C
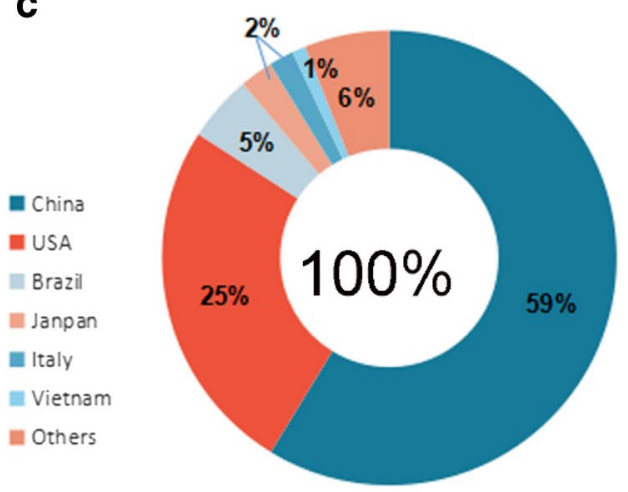

e

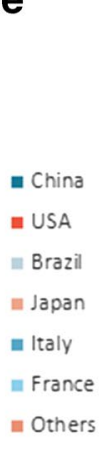

b

- China

- USA

III France

in Italy

- Brazil

= Japan

\# Others

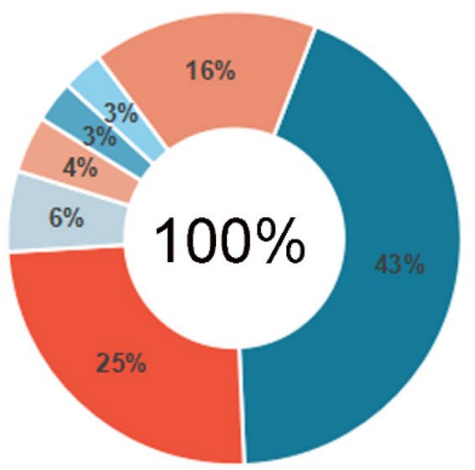

d

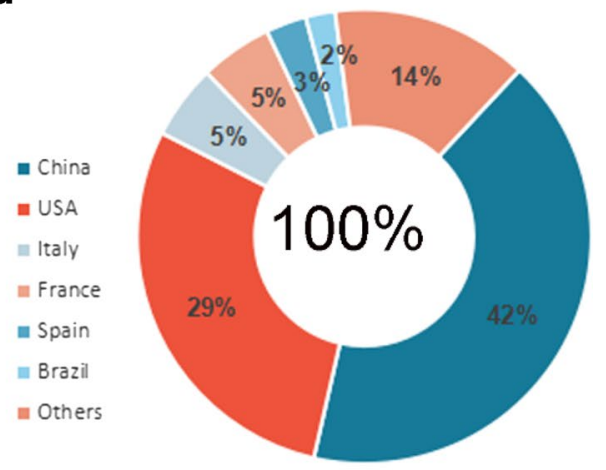

f
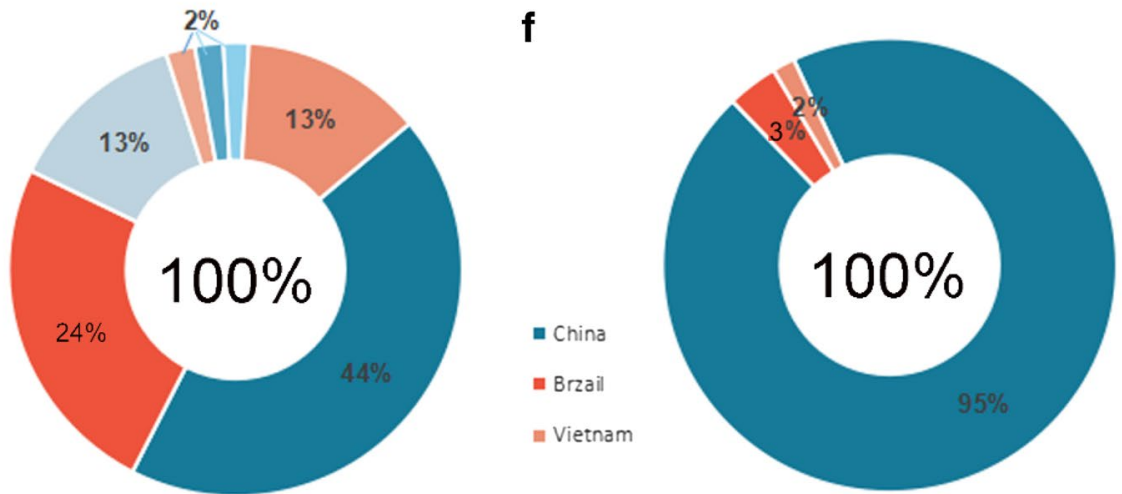

Fig. 5 The ratio of suitable areas in the world of six typical Illicium plants. (a I. verum; b I. henryi; c I. majus; $\mathbf{d}$ I. simonsii; e I. micranthum, f I. difengpi)

$\mathrm{km}^{2}$, or equivalent to $1 \%$ of the total area worldwide, in Japan and Brazil. A large proportion of the area corresponding to $45.4 \times 10^{4} \mathrm{~km}^{2}(98 \%)$ is mainly distributed in Anhui, Zhejiang, Guangxi, and Guangdong provinces in China.

j. I. difengpi B. N. Chamg prevailingly grows in Guangxi and Yunnan, China and is recorded as endangered in the Endangered Species Act, it covers a potential suitable area of $20.1 \times 10^{4} \mathrm{~km}^{2}$. This species is distributed in $0.7 \times 10^{4}(3 \%)$ and $0.3 \times 10^{4}$ $\mathrm{km}^{2}(2 \%)$ in Vietnam and Brazil, respectively. Its largest suitable area is $19.0 \times 10^{4} \mathrm{~km}^{2}$ (95\%), which is mainly located in Guangxi and southeast of Yunnan in China.

k. I. ternstroemioides A. C. Smith, a native species in China, mainly in Hainan, has a total potential suitable area of $88.7 \times 10^{4} \mathrm{~km}^{2}$. This species covers $6.8 \times 10^{4}(8 \%)$ and $4.3 \times 10^{4} \mathrm{~km}^{2}(5 \%)$ in Brazil and Vietnam, respectively. The core areas measuring $76.7 \times 10^{4} \mathrm{~km}^{2}(85 \%)$ are mainly located in Hainan, Fujian, Hunan, and Guangdong provinces in China.

1. I. macranthum A. C. Smith primarily occurred in Yunnan, China, has a total potential suitable area of $89.9 \times 10^{4} \mathrm{~km}^{2}$. This species is distributed in 

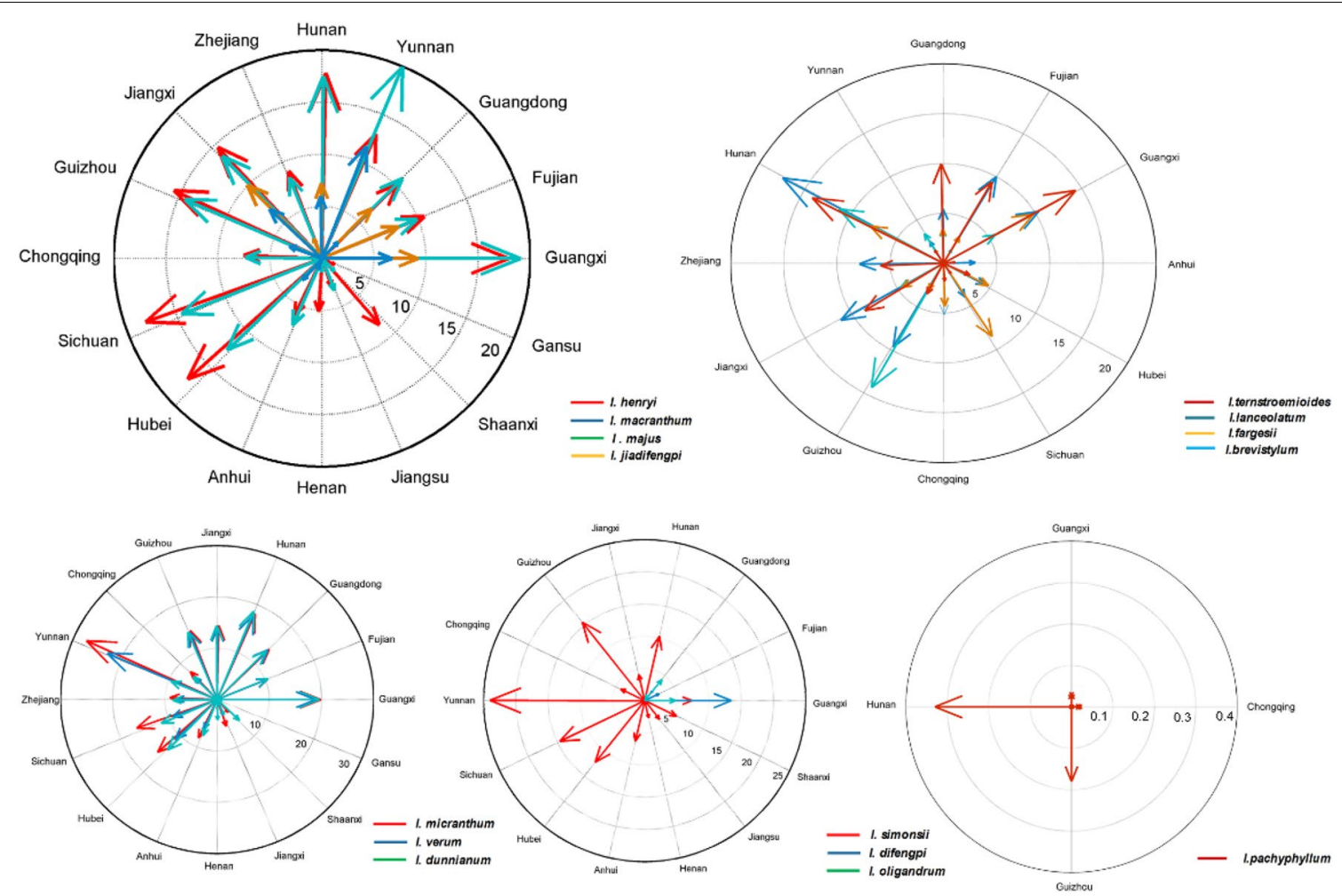

Fig. 6 Suitable areas in every provinces in China of 15 illicium plants

areas of $27.3 \times 10^{4}(30 \%)$ and $9.6 \times 10^{4} \mathrm{~km}^{2}(12 \%)$ in the USA and Brazil, respectively. This species also occupies the largest suitable habitat area of $44.6 \times 10^{4} \mathrm{~km}^{2}$ (49\%) found in Yunnan and Jiangxi provinces in China.

m. I. oligandrum Merr.et Chun, chiefly grows in Guangxi and Hainan from China, has a total potential suitable area of $13.6 \times 10^{4} \mathrm{~km}^{2}$. This species respectively covers $2.53 \times 10^{4}(18 \%)$ and $9.9 \times 10^{4}$ $\mathrm{km}^{2}$ in Vietnam and China (Guangdong and Guangxi provinces), and this coverage accounts for $73 \%$ of the total area worldwide.

n. I. brevistylum A. C. Smith, a species endemic to China, mainly in Fujian and Hunan, has a globally potential distribution area of $31.8 \times 10^{4} \mathrm{~km}^{2}$. It covers $0.6 \times 10^{4} \mathrm{~km}^{2}(2 \%)$ in Japan and $31.2 \times 10^{4} \mathrm{~km}^{2}$ (98\%) in other regions, such as Fujian, Guangdong, Guangxi, and Hunan provinces in China.

o. I. pachyphyllum A. C. Smith, another species endemic to China, principally in Hunan and Guangdong, has a potential suitable habitat with an area of $0.5 \times 10^{4} \mathrm{~km}^{2}$ in Hunan, Guizhou, and Guangxi provinces in China. This observation is consistent with our current findings.

\section{Discussion}

In this study, spatial analysis was conducted using GMPGIS to define the spatial distribution of habitat suitability and the range of each variable for two classes of habitats of 15 Illicium species. According to the analysis of environmental variables, it is easy to be concluded that different Illicium species exist in different requirement on a growing environment. In addition, Our GMPGIS models successfully showed that the most suitable climate condition for these plants are annual mean temperature of $11.5-22.0{ }^{\circ} \mathrm{C}$, mean temperature of $-0.7-16.9{ }^{\circ} \mathrm{C}$ in the coldest quarter, and annual precipitation of 551-2016 mm, in which are roughly consistent with the known regions where the 15 Illicium species exist and mostly located in a large range from $\mathrm{S} 45^{\circ}$ to $\mathrm{N}$ $45^{\circ}$. On the basis of the climatic suitable maps of these plants, we can conclude that they covered an area of $1356.75 \times 10^{4} \mathrm{~km}^{2}$ in China, which ranked first, followed by the USA with an area of $527.42 \times 10^{4} \mathrm{~km}^{2}$. We speculated that the reason for China topped the rankings is not only China has vast areas could grow Illicium plants, but also there are many endemic species in China such as I. fargesii, I. brevistylum and I. pachyphyllum. I. verum with a high shikimic acid content is mainly distributed 
in China (48\%) and in the USA (19\%). The suitable habitats of I. difengpi cover 95, 3, and 2\% in China, Brazil, and Vietnam, respectively.

\section{Conclusion}

According to the data on suitable habitats, we recommended that $I$. verum can be expanded to suitable regions, such as southeast of China and south of Brazil, to solve problems on shikimic acid shortage. I. difengpi can be introduced to Vietnam and Brazil and can thus mitigate its risk of becoming endangered. Some species, such as $I$. henryi, I. micranthum, and I. dunnianum, which are endemic to China, can be introduced and cultivated in the USA or other favorable regions. This approach possibly addresses the high demands for shikimic acid, protects the diversity of rare or endangered species, and helps governments establish various protection strategies for future ecological conservation.

\section{Additional files}

Additional file 1: Table S1. The range of the latitude and longitude of the sampling points. Table S2. The specific areas in each countries of the world. Table S3. The specific areas in each provinces of China.

Additional file 2. Minimum standards of reporting checklist.

Additional file 3: Figure S1. The ratio of suitable areas in the world of the other 9 Illicium plants ( $a$, I. dunnianum; b, I. lanceolatum; c, I. fargesii; d, I. jiadifengpi; e, I. ternstroemioides; f, I. macranthum; g, I. oligandrum; h,l. brevistylum; i, I. pachyphyllum).

\section{Abbreviations}

GMPGIS: geographic information system for global medicinal plants; CVH: Chinese Virtual Herbarium; NSII: National Specimen Information Infrastructure.

\section{Authors' contributions}

LFH and SLC conceived the ideas and designed methodology; XZ collected and analyzed the data of 15 Illicium species together with XXM and JW; XZ was a major contributor in writing the manuscript. All authors read and approved the final manuscript.

\section{Acknowledgements}

This study is supported and sponsored by the National Natural Science Foundation of China (No. 81473315) and the CAMS Innovation Fund for Medical Sciences, Grant CIFMS (No. 2016-12M-3-015).

\section{Competing interests}

The authors declare that they have no competing interests.

\section{Availability of data and materials}

The readers can use data and materials in this manuscript by quotation of author names and Journal of Chinese Medicine.

\section{Consent for publication}

All of authors consent to publication of this study in Journal of Chinese Medicine.

Ethics approval and consent to participate Not applicable.

\section{Funding}

This study was supported by the National Natural Science Foundation of China (No. 81473315) and the CAMS Innovation Fund for Medical Sciences, Grant CIFMS (No. 2016-12M-3-015).

\section{Publisher's Note}

Springer Nature remains neutral with regard to jurisdictional claims in published maps and institutional affiliations.

Received: 23 March 2018 Accepted: 31 May 2018

Published online: 15 June 2018

\section{References}

1. Rawat G, Tripathi P, Saxena RK. Expanding horizons of shikimic acid. Appl Microbiol Biotechnol. 2013;97:4277-87.

2. Bochkov DV, Sysolyatin SV, Kalashnikov Al, Surmacheva IA. Shikimic acid: review of its analytical, isolation, and purification techniques from plant and microbial sources. J Chem Biol. 2012;5:5-17.

3. Farina V, Brown JD. Tamiflu: the supply problem. Angew Chem. 2006;45(44):7330-4. https://doi.org/10.1002/anie.200602623.

4. Pang X. Research progress in shikimic acid. Heilongjiang Med J. 2011;24(5):700-2.

5. Li G, Du S, Wen Z. Mapping the climatic suitable habitat of oriental arborvitae (Platycladus orientalis) for introduction and cultivation at a global scale. Sci Rep. 2016;6:30009.

6. Lin Q. Medicinal plant resources of Illicium L. Chin Tradit Herbal Drugs. 2002;2002(7):81-4.

7. Yi YJ, Cheng X, Yang ZF, Zhang SH. Maxent modeling for predicting the potential distribution of endangered medicinal plant (H. riparia Lour) in Yunnan, China. Ecol Eng. 2016;92:260-9.

8. Box JM, Harwood LM, Humphreys JL, Morris GA, Redon PM, Whitehead RC. Dehydration of quinate derivatives: synthesis of a difluoromethylene homologue of shikimic acid. Synlett. 2002;2002:0358-60.

9. Ghosh S, Chisti Y, Banerjee UC. Production of shikimic acid. Biotechnol Adv. 2012:30:1425.

10. Nie LD, Shi XX, Ko KH, Lu WD. A short and practical synthesis of oseltamivir phosphate (Tamiflu) from (-)-shikimic acid. J Org Chem. 2009;74:3970.

11. Huang LF, Wang ZH, Chen SL. Hypericin: chemical synthesis and biosynthesis. Chin J Nat Med. 2014;12:81-8.

12. Zhang, LuT, Zhang H, Cheng FM, Liu J. Recent progress in the synthesis of tamiflu. Chin J Org Chem. 2013;33:1235.

13. Kou YH, Lei Y. Synthesis of shikimic acid. J Shaanxi Univ Sci Technol. 2011;29(3):53-9.

14. Zhan $Y$, Ouyang $H$. The study on the process of application and preparation of Shikimic acid. Chem Intermed. 2012;9(5):1-5.

15. Liu Y. Research advance in Shikimic acid. Chem Ind Times. 2007;2007(3):54-7.

16. Guo Y, Li X, Zhao Z, Wei H, Gao B, Gu W. Prediction of the potential geographic distribution of the ectomycorrhizal mushroom Tricholoma matsutake under multiple climate change scenarios. Sci Rep. 2017;7:46221.

17. Manyangadze T, Chimbari MJ, Gebreslasie M, Ceccato P, Mukaratirwa S. Modelling the spatial and seasonal distribution of suitable habitats of schistosomiasis intermediate host snails using Maxent in Ndumo area, KwaZulu-Natal Province, South Africa. Parasites Vectors. 2016;9:572.

18. Liang S, Jie WU, Xi-Wen LI, Jiang XU, Dong LL, Sang MC, Sun CZ, Fujihara N, Chen SL. A study of global ecological adaptability and field selection practices of Panax ginseng. China J Chin Mater Med. 2016;41(18):3314-22.

19. Liu D, Wang R, Gordon DR, Sun X, Chen L, Wang Y. Predicting plant invasions following China's Water Diversion Project. Environ Sci Technol. 2017:51:1450.

20. Meng XX, Huang LF, Dong LL, Xi-Wen LI, Wei FG, Chen ZJ, Jie WU, Sun CZ, Yu-Qi YU, Chen SL. Analysis of global ecology of Panax notoginseng in suitability and quality. Acta Pharm Sin. 2016;51(9):1483-93.

21. Huang L, Xie C, Duan B, Chen S. Mapping the potential distribution of high artemisinin-yielding Artemisia annua L. (Qinghao) in China with a geographic information system. Chin Med. 2010;5:18. 